\title{
In-depth Interpretation of Listening in on English Monologues
}

\author{
Fengshuo Zhang* \\ Xi'an Gaoling No.1 Senior High School, Xi'an 710200, Shaanxi Province, China \\ *Corresponding author: Fengshuo Zhang, 15029962010@163.com
}

\begin{abstract}
There exists some difficulties among high school students in understanding English monologues because some words are unfamiliar to them while some sentences are long and complex. Just by listening, reading, and translating from English into Mandarin, the students are unable to fully grasp the conveyed messages in these monologues. In the General Senior High School Curriculum Standards (2017 Edition), it clearly required candidates to be able to understand familiar short dialogues and monologues about daily life topics. Candidates should be able to understand the gist, obtain specific factual information, make simple inferences about what they are listening to, and understand the speaker's intention, views, as well as attitude. This article mainly discusses specific implementation strategies of in-depth interpretation when listening in on monologues.
\end{abstract}

Keywords: Listening in on monologues; In-depth interpretation

Publication date: July 2021; Online publication: July 30, 2021

\section{Introduction}

Generally, the words used in monologues are much easier than those in other reading materials but it does not mean that students with average English levels can understand all the words in these monologues. During the National English Test Volume II in 2020, there are many difficult words such as "delay," "delete," "cancel," and "functional" which are unfamiliar to many students who have limited vocabularies. In addition, there are many long and complex sentences in monologues which are hard to understand for students who have poor grammar.

After interviewing the students from Class Four, Grade One in Gaoling No.1 Senior High School, Xi'an City, Shaanxi Province, it is found that a small number of students are not able to thoroughly understand the monologue even when the listening text has been shown to them due to many difficult words or complex sentences. However, those problems can be solved by in-depth interpretation of listening in on monologues.

\section{Present situation of listening in on monologues teaching}

In the process of teaching listening in many senior high schools, listening texts are rarely used. For most teachers, the teaching process is very simple whereby the teaching mode of "play the tape - answer the questions - check the answers - read the text" is often adopted ${ }^{[1]}$. In reality, the teaching of listening in on monologues is usually conducted by one of the ways discussed below. 


\subsection{Listening}

Many teachers do not display the written words of the monologue or explain the difficult words. They would just allow the students to listen again and again without any explanation regarding the listening text. Even worse, none of the listening texts are shown to the students. As a result, students who are weak in English listening can never have a thorough understanding about the content and by checking their answers, it does not put an end to their confusion. With this teaching method, many students feel sleepy during the listening class.

\subsection{Listening and reading}

After checking the answers, some teachers would ask their students to read the text of the monologue when there is some time left. For students with a large vocabulary, there is no trouble understanding the listening text. However, for students who have poor vocabulary, it is impossible for them to precisely understand the whole passage on their own.

\subsection{Listening, reading, and translating}

There are some teachers who explain the contents to their students. Yet, it is a pity that they translate the text into Mandarin in which the students would just understand the literal meaning. Chances are that the speaker's intention, views, and attitude would not be conveyed to the students. In addition, the beauty of the language and the ingenuity of the sentence patterns cannot be fully appreciated and learned.

\section{Strategies for in-depth interpretation when listening to English monologues}

Listening is a basic skill in language learning. In the General Senior High School Curriculum Standards (2017 Edition), it clearly required candidates to be able to understand familiar short conversations and monologues about daily life topics. Candidates should be able to understand the main themes, obtain specific factual information, make simple inferences of the content, and understand the intention, views, and attitude of the speaker ${ }^{[2]}$. The teachers' interpretations of the monologues determine the choice of teaching modes and the effect of teaching designs which also directly affect the students' learning experience, cognitive development, emotional participation, and learning effect ${ }^{[3]}$.

\subsection{Summarizing the main idea}

In most cases, listening in on monologues include a lot of specific factual information. The first step of indepth interpretation when listening in on monologues is to summarize the main idea which helps students to have a comprehensive understanding of the whole text and avoid the phenomenon of "only seeing the trees but not the forest."

The tenth paragraph of the second-month test paper, Module One in Senior High School English Listening published by Shaanxi People's Education Press is as follows:

Mrs. White, 72 years old, visited a store while doing some shopping but did not buy anything. She was followed through the town by the store manager. He had been told that a customer saw her took a greeting card and put it in her shopping bag. He stopped her at a bookstore as she was reading a book. Mrs. White said, "This man, a total stranger, suddenly grasp my bag and asked if he could look in it." She was taken back to the store and shut in a small room in full view of shoppers for 20 minutes until the police arrived. At the police station, she was searched but nothing was found.

So yesterday, the elderly woman made a legal claim against the department store because it had 
wrongly accused her of stealing a card. She claimed \$3,000 damages from the store for wrongful arrest.

Her lawyer said that the department store sent an insincere apology and they insisted that she might have been stealing. The hearing continues today.

Using this, the teacher has asked the students to summarize the main idea. At the beginning, the students wrote:

A woman who was accused of stealing a card was searched by the police but nothing was found. She claimed \$3,000 damages but the store insisted that she might have been stealing.

Then, the teacher requested the students to reorganize the summary into one sentence in which the students deleted some procedural information and concluded:

A woman claimed $\$ 3000$ for being wrongly accused of stealing a card.

Through the above process of integrating information, the students' language ability and summarizing ability have improved.

\subsection{Interpreting difficult words and analyzing long sentences}

Monologue texts need to be learned with a lot of time and energy. Although the three-dimensional goals are equally important, an individual should not favor one over the other. In practice, teachers should not "grasp the eyebrows and moustaches" otherwise, it will be difficult to find a breakthrough in teaching and in guiding students to carry out in-depth monologue interpretations within a limited time ${ }^{[4]}$.

In the training of listening, there is a principle that is easily neglected which is, "you can only understand what you can read at most ${ }^{[5]}$." Therefore, it is necessary for teachers to explain difficult words in regard to pronunciation, spelling, and meaning as well as analyze long and difficult sentences in order to ensure that students understand the grammar rules involved.

In the tenth paragraph of Level C, Unit Three, Module One in Senior High School English Listening, published by Shaanxi People's Education Press, there are a few sentences as follows:

When the sun rose, the men saw land and jumped from ice sheet to ice sheet before a fishing boat rescued them. The men had wounds on their feet but were in good shape.

In the above passage, there is a new word which will be learned which is "rescue" and there are also some unfamiliar words to the students such as "sheet," "wounds," and "shape." From the perspective of the sentence structure, there is an adverbial clause of time guided by "before" which is probably difficult for students to understand. Therefore, after asking the students to read aloud, the teacher focused on analyzing the meanings of the difficult words and then, requested the students to translate the sentences into Mandarin. As expected, the students have accurate understanding of the sentences which could be seen from their oral translations.

The content of the above listening text is alike news and it is close to what is seen in daily life in which the words are very vivid. In the process of reading, pictures would flash through the students' minds. Therefore, students can easily grasp the meaning of the monologue text through imagination. In addition, with interesting and vivid language, students would be interested in it, hence learning fast and well. 


\subsection{Inferring implied information}

At times, listening in on monologues only provides some factual information while the implied information, which is the key to understanding the content of the listening text, needs to be dug out by the listeners themselves. If the explanation only refers to the literal meaning, the students would not be certain whether their understanding is acceptable or not.

In the tenth paragraph of Level C, Unit One, Module Two in Senior High School English Listening, published by Shaanxi People's Education Press, there is a passage as follows:

A little boy did not say a word until he was three years old. His mother took him to every doctor but there was no use. He was healthy and bright, so the doctors told his mother not to worry.

One morning, the boy suddenly knocked on the table and cried out, "These eggs are terrible!" The mother was very glad at hearing her son speak and asked, "Why didn't you say anything before?"

"Well," he answered, "up to now, the eggs have been very good."

The words used in the above listening text are not difficult at all. The literal meaning is clear but the implied information needs to be inferred by the listener. In order to thoroughly understand the above text and improve students' thinking ability, three questions should be asked:

a. What is the matter with the eggs in the morning when the boy spoke?

b. Could the boy speak before he was three years old?

c. Why did not the boy say any words before he was three years old?

By answering the first two questions, students can easily obtain the possible answer to the third question which refers to the key issue of the text in which "the boy thought there was no need for him to speak."

\subsection{Exploring the speaker's intention, views, and attitude}

Chances are that the intention, views, and attitude of the speaker reflected in the monologue are different from the listeners. If the listeners hold on the views and attitude of things that they have formed to make comments on the targeted sentences, they are likely to get the wrong idea. In order to understand the speaker's intention, views, and attitude, the listeners need to search for relevant information.

In the tenth paragraph of Level B, Unit Four, Module Two in Senior High School English Listening, published by Shaanxi People's Education Press, there is a passage as follows:

Michael Jackson was the biggest popstar of the 1980s, and certainly one of the most popular recording artists of all time. His 1982 Thriller became the best-selling album of all time. He was the first black artist to become famous on MTV.

Michael Jackson was born on August 29, 1958 and was the fifth son of Joe Jackson. Michael showed a talent for music and dancing from a young age. His father began to organize a family musical group with his three eldest sons in 1962 and Michael joined them in 1964. The group, named the Jackson 5, released their first single performance in October 1969. Michael was just 11 years old then. I Want You Back, ABC, The Love You Save, and I'll Be There all hit No.1 in 1970! Later in 1972, Michael had his first No.1 single titled, Ben. In 1977, he met the producer and composer, Quincy Jones for the first time. With Jones producing, Michael recorded his first album, Off the Wall as an adult.

After analyzing the long sentences with difficult words in the text, the following questions should be asked: 
a. What is the speaker's attitude toward Michael Jackson?

b. How do you know that?

By looking at the phrases such as "biggest popstar," "popular recording artists," "the first black artist," "showed a talent for music and dancing" used by the speaker to describe Michael Jackson, it is not difficult to draw a conclusion that the above words are all factual descriptions. Therefore, the speaker's attitude toward Michael Jackson is objective and not commendatory or derogatory.

\section{Conclusion}

It is not enough to teach listening simply by listening, reading, and translating. Listening in on monologues are very meaningful and full of information which are also permeated with humanistic characteristics and cultural charm. In-depth interpretation when listening in on monologues which is of great significance in the teaching of English listening does not only improves students' linguistic competence but also their thinking ability, cultural awareness, and learning ability. This simple extra step can ensure that there is no regret or confusion in students' training of listening.

\section{Disclosure statement}

The author declares that there is no conflict of interest.

\section{References}

[1] Zhu X, 2020, Building a Listening Teaching Framework to Improve Students' Thinking Ability. English Teaching and Research in Primary and Secondary Schools, (6): 42-46.

[2] Zhang Z, 2018, Current Situation and Teaching Strategies of English Listening Teaching in Rural High Schools. New Oriental English High School Students, (4): 94.

[3] Chen Y, 2019, Reading Levels and Effective Achievement in English Reading Teaching. Foreign Language Teaching in Primary and Secondary Schools (High School), 42(2): 23-8.

[4] Wang W, 2020, Exploration on the Path of Deep Interpretation of High School English Monologues. English Teaching and Research in Primary and Secondary Schools, (6): 21-4.

[5] Gao X, 2019, How to Improve English Listening. http://yingyu.xdf.cn/201702/10615159.html (assessed on 11/18/2019). 